to cells (think of the number of cellular states in an ecosystem of even moderate complexity!) makes serious reading impossible. But if these ideas are not ultimately to be tested, what are they for?

Another disturbing feature of Adaptability is the apparently innocent way in which it runs across the mine fields of group selection, species selection and ecosystem selection in their many and arguable forms. Statements such as "Some traits might only be mildly disadvantageous to the species", "The community may use its adaptability to buffer the controllable environment from the uncertain perturbations of the uncontrollable environment" and "ecosystems will tend to develop in directions which eliminate . . . unnecessary cost for the biota" will raise Darwinian hackles, yet appear throughout the text. If Conrad realizes that these are contentious statements he gives precious few indications of the fact.

Was the struggle worth while? The honest answer is "no". When I finished the text, I was no wiser about "The significance of variability from molecule to ecosystem" than I was when I started. I have a sneaking suspicion that there may be some novel and worthwhile ideas hidden in there, but like the Cheshire cat, they are awfully difficult to find.

John Lawton is a Reader in the Department of Biology at the University of York.

\section{Out on a limb}

\section{T.M.L. Wigley}

\section{Past Climates: Tree Thermometers,}

Commodities and People.

By Leona Marshall Libby.

University of Texas Press: 1983. Pp.142.

$£ 21.25, \$ 25$.

THE cover design is excellent; a negative picture of a section of tree on a tasteful beige background, with the main title Past Climates arrestingly clear. But don't be misled. You'll learn precious little from this book about past climates, for the pages give only a highly personal view of two avenues of research into climate reconstruction that the author has explored. The restricted scope of the book is described in its subtitle. A chance to learn about dendroclimatology (Tree Thermometers) and about the effects of climate on society (Commodities and People), perhaps? Wrong again.

The first half of the book describes Libby's attempts to extract information about past climatic change from the stable isotopic composition of accurately dated wood samples. Some of this work was originally published in Nature, a sad comment on the fallibility of the refereeing system. Libby was one of the early workers in this field, but her work and results are viewed with considerable scepticism by other isotope climatologists. I thought that here Libby might be able to justify her particular approach, point out where other workers have gone astray, or reconcile the differences of opinion which exist. But no. None of the recent advances in our understanding - through the work of Ferhi and Letolle, Stuiver and Burk, Francey and Farquhar, Gray and Thompson, and others - is mentioned. All other work is summarily dismissed on the grounds that the analyses are based on "wet chemistry".

Libby adheres to her semi-empirical approach and all her book succeeds in is to document its inadequacies, errors and oversimplifications. As an example, consider her suggestion that the isotopic composition of local precipitation is related to sea-surface temperature in the water vapour source region, and to local temperatures. Both suggestions are wrong, and it certainly can't be both. In attempting to support the suggested link Libby only considers the similarity of the seasonal cycles of precipitation $\delta^{18} \mathrm{O}$ and temperature - an irrelevant comparison. Although the link with local temperatures is one which is commonly assumed, it is not confirmed by an analysis of IAEA data on precipitation $\delta^{18} \mathrm{O}$ values. In general, interannual $\delta^{18} \mathrm{O}$ variations do not correlate with interannual variations in local temperature.

Some of Libby's data do show vague trends which are similar to changes in temperature over the same period. For example, she compares German oak data with winter temperatures (in England) and Californian sequoia data with summer temperatures. (The argument in the latter case is that sequoias grow mainly in summer, so I suppose the oak must be assumed to grow in winter.) In none of these comparisons are any quantitative correlations calculated. Rigorous statistical testing of hypotheses is eschewed in other aspects of her work. For example, a purported relationship between normalized wheat prices and temperature turns out to be insignificant if due allowance is made for the effects of autocorrelation.

The final section of the book, "Human Interaction with Climate", I found to be interesting, but, in common with many other similar works on this subject, generally unconvincing. It is all too easy to interpret parallels in the timing of social and climatic events (both of which tend to be poorly dated) in a deterministic sense; and while such interpretations may be provocative they are usually scientifically unsatisfying.

Overall, this book has little to offer to the discipline of climatology. It must be one of life's small ironies that the author's name is an anagram of "alone". In this field, she is.

T.M.L. Wigley is Director of the Climatic Research Unit at the University of East Anglia.

\title{
Fertile matter
}

\section{R.J. Aitken}

Reproductive Physiology of Vertebrates. 2nd edn

By Ari van Teinhoven.

Cornell University Press, Ithaca and

London: 1983. Pp.560. £42, \$49.50.

As a young graduate tackling the complexities and bewildering diversity of vertebrate reproduction, I was frequently grateful for the presence of Ari van Tienhovens' Reproductive Physiology of Vertebrates (that is, until it was permanently borrowed by a colleague who clearly shared my appreciation of Van Tiehoven's ability to précis a vast literature). The recent issue of an updated and improved version of this impressive work is therefore to be welcomed, not only because it will replace an eight-year-old gap in my bookshelf but also because it will benefit a new generation of biology graduates seeking to increase the depth and breadth of their understanding of vertebrate reproduction.

It is in the scope of the text that the uniqueness and importance of this book lies. The list of species and topics covered is comprehensive, taking us from cyclostomes to humans on a range of subjects, covering the gamut of reproductive phenomena. The layout of the book is logical and an improvement on the first edition in many respects, incorporating new chapters on such key subjects as puberty, intersexes and immunological aspects of reproduction. The comparative nature of the text is also backed up by helpful diagrams and especially tables, many of which summarize volumes of data.

From the text one gains an insight into the lability of the reproductive process which can apparently adapt, in an infinite variety of ways, to meet the particular requirements of a species. Fascinating examples of this diversity include the 'delayed implantation' exhibited by certain mammalian species (such as roe deer, skunks, polar bears and wallabies) in which the embryo is held in a dormant state within the uterus for months on end, only to be suddenly activated at a time which will heip ensure the subsequent survival of the young.

Even more bizarre is the phenomenon of gynogenesis exhibited by certain species of fish, of which only female forms exist. Having dispensed with the need for males, such species reproduce by annexing the spermatozoa of other teleost species to penetrate and initiate the parthenogenetic development of their ova.

No man can be an expert in all things however and, given the range of material reviewed by the author, it is understandable if small inaccuracies creep in, such as the notion that sperm-oocyte interaction does not exhibit species specificity or that 